Cold Regions Research \& Engineering Laboratory

\title{
Investigations of Explosives and Their Conjugated Transformation Products in Biotreatment Matrices
}

Philip G. Thome and Daniel C. Leggett

February 1999 
Abstract: Samples of soil that had been aerobically composted or anaerobically digested were extracted with solvent, then hydrolyzed with base and then acid. The concentrations of extractable TNT and its monoamino and diamino transformation products fell rapidly after the first days of treatment. Hydrolysis of the solventextracted residues released significant quantities of intact transformation products. The concentrations of RDX and $H M X$ were reduced in a similar fashion without the appearance of significant quantities of transformation products. A generalized approach to biotreatment matrices analyses was developed. Spike-recovery studies indicated that analyses of bioremediation matrices should be considered as a qualitative descriptor of the progress of humification and the capacity to covalenty conjugate transformation products rather than as a quantitative measure of the absolute amounts of various analytes present.

\section{How to get copies of CRREL technical publications:}

Department of Defense personnel and contractors may order reports through the Defense Technical Information Center:

DTIC-BR SUITE 0944

8725 J OHN J KINGMAN RD

FT BELVOIR VA 22060-6218

Telephone 18002253842

E-mail help@dtic.mil

msorders@dtic.mil

WWW http://www.dtic.dla.mil/

All others may order reports through the National Technical Information Service: NTIS

5285 PORT ROYAL RD

SPRINGFIELD VA 22161

Telephone 18005536847 or 17036056000

17034874639 (TDD for the hearing-impaired)

E-mail orders@ntis.fedworld.gov

WWW http://www.ntis.gov

A complete list of all CRREL technical publications is available from:

USACRREL (CECRL-IB)

72 LYME RD

HANOVER NH 03755-1290

Telephone 16036464338

E-mail techpubs@crrel.usace.army.mil

For information on all aspects of the Cold Regions Research and Engineering Laboratory, visit our World Wide Web site: http://www.crrel.usace.army.mil 


\section{Special Report 99-3}

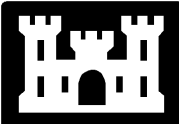

US Army Corps of Engineers $\circledast$

Cold Regions Research \&

Engineering Laboratory

\section{Investigations of Explosives and Their Conjugated Transformation Products in Biotreatment Matrices}

Philip G. Thome and Daniel C. Leggett

February 1999 


\section{PREFACE}

This report was prepared by Philip G. Thorne, Research Physical Scientist, Geological Sciences Division, and Daniel C. Leggett, Research Chemist, Geochemical Sciences Division, U.S. Army Cold Regions Research and Engineering Laboratory (CRREL), Hanover, New Hampshire.

Funding for this work was provided by the U.S. Army's Strategic Environmental Research and Development Program (Project \#715), Arlington, Virginia, Judith C. Pennington, Project Monitor, and by the U.S. Army Environmental Center, Aberdeen Proving Ground, Maryland, Martin H. Stutz, Project Monitor. The cooperation of Dr. Thomas Jenkins, CRREL; Harry Craig, EPA; Elona Tuomi, ReTec; Ginger Fergusen and Andy Markos, Black and Veatch; Neal Adrian, U.S. Army Construction Engineering Research Laboratories; and William Lowe, Roy F. Weston, is greatly appreciated.

The authors gratefully acknowledge Dr. Charles M. Reynolds and Marianne E. Walsh, CRREL, for their technical reviews of this manuscript, and Dr. Clarence L. Grant, Professor Emeritus, University of New Hampshire, for helpful comments.

This publication reflects the personal views of the authors and does not suggest or reflect the policy, practices, programs, or doctrine of the U.S. Army or government of the United States. The contents of this report are not to be used for advertising or promotional purposes. Citation of brand names does not constitute an official endorsement or approval of the use of such commercial products. 


\section{CONTENTS}

Preface

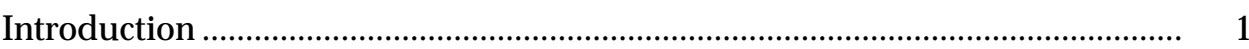

Materials and methods ................................................................................ 2

Composts and digester sludges ……….................................................... 2

Analytical methods ..................................................................................... 2

Solvent extraction ............................................................................... 2

Acid hydrolysis ......................................................................................... 3

Base/acid hydrolysis ............................................................................. 3

Recoveries .......................................................................................... 3

Analysis for triaminotoluene in anaerobic cultures ...................................... 4

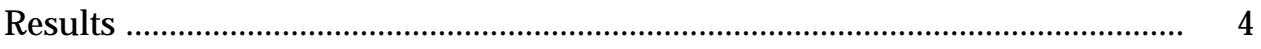

Solvent extraction ............................................................................... 4

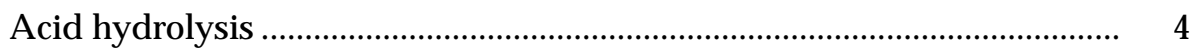

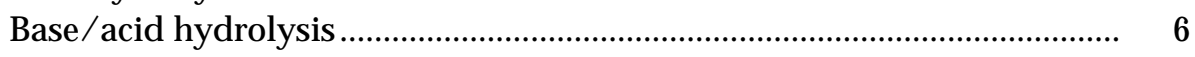

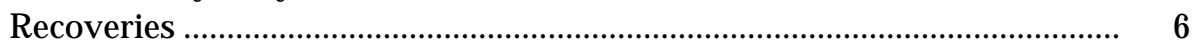

Analysis for triaminotoluene in anaerobic cultures .................................. 10

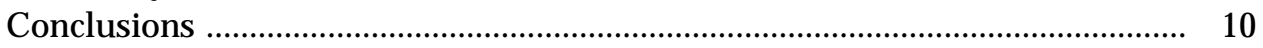

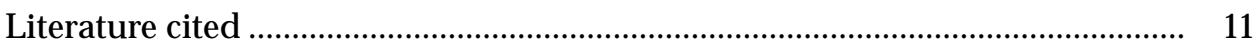

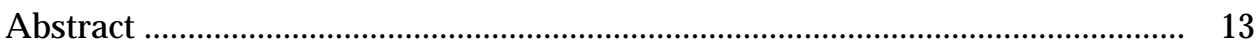

\section{ILLUSTRATIONS}

Figure Page

1. Concentration of free TNT and free and conjugated transformation products recovered from aerated compost.

2. Comparison between the recoveries of ADNT and DANT transformation products from Day-15 aerated compost using acetonitrile extraction, acid digestion, and base/acid digestion

3. Concentration of free TNT and free and conjugated transformation products recovered from digester sludge

\section{TABLES}

Table Page

1. Gradient elution, LC-CN conditions for triaminotoluene ……………………....... 4

2. Umatilla windrow composts, time series, aerated ............................................... 5

3. Percent recoveries of spikes by acetonitrile extraction ............................................ 8

4. Effect of neutralization $\mathrm{pH}$ on percent recovery of hydrolyzed spikes .................... 8

5. Recovery of transformation products from compost using $100 \%$ or $50 \% \mathrm{H}_{2} \mathrm{SO}_{4}$ after base hydrolysis ................................................... 9

6. Percent recoveries from base/acid hydrolyzed solution, compost, and sand 


\title{
Investigations of Explosives and Their Conjugated Transformation Products in Biotreatment Matrices
}

\author{
PHILIP G. THORNE AND DANIEL C. LEGGETT
}

\section{INTRODUCTION}

Previous work on biotreatment of TNTcontaminated soils indicates that TNT is rapidly converted to solvent-extractable transformation products and to residues that are conjugated in a non-solvent-extractable form (Kaplan and Kaplan 1982, Caton et al. 1994, Pennington et al. 1995). Plants grown hydroponically in TNT solutions metabolized TNT reductively and transformation residues were partially conjugated in a nonsolvent-extractable form (Palazzo and Leggett 1986a, b; Harvey et al. 1990). A considerable quantity of the two aminodinitrotoluene (ADNT) transformation products was released by acid hydrolysis of the harvested plants after first extracting unconjugated transformation products with benzene (Palazzo and Leggett 1986a, b).

In experiments at Oak Ridge National Laboratory, base hydrolysis following solvent extraction recovered an additional $60 \%$ of the applied radiolabel from TNT/soil composts after 90 days (Caton et al. 1994). Although the hydrolysates were not analyzed for specific TNT transformation products, the analogy between living plants and remediation systems containing mostly plant matter and wastes suggested that standard highpressure liquid chromatography (HPLC) analysis of hydrolysates could be used to identify and quantify conjugated TNT residues in compost and digester sludge.

TNT transformation and disposition in the environment has been thoroughly discussed in several reviews (McCormick et al. 1976, Walsh 1990, Gorontzy et al. 1994). The biological reduction of the nitro groups on TNT proceeds through nitroso and hydroxylamine intermediates to two aminodinitrotoluene isomers (ADNTs), 4-amino2,6-dinitrotoluene (4ADNT) and 2-amino-4,6dinitrotoluene (2ADNT), and two diaminonitrotoluene isomers (DANTs), 2,4-diamino6-nitrotoluene (2,4DANT) and 2,6-diamino-4nitrotoluene (2,6DANT). The condensation of hydroxylamine intermediates to form azoxy dimers has also been reported (McCormick et al. 1976, Kaplan and Kaplan 1982, Spanggord et al. 1995). The reduction pathways for TNT appear to be essentially the same in a wide diversity of species and environmental systems, including mammals, higher and lower plants, bacteria, soil, activated sludge, and compost. However, the predominant amino isomer is 4ADNT in aerobic systems and 2ADNT in anaerobic systems (Carpenter et al. 1978, Pennington 1988, Harvey et al. 1990).

The experiments of Thorn et al. (1996 a, b) using ${ }^{15} \mathrm{~N}-\mathrm{NMR}$ to study covalent conjugation of the aromatic amine aniline to humic substances and whole peat provide the best model for explaining the fate of aromatic amine and diamine TNT transformation products. Aniline was reacted with purified humic and fulvic acids, silt loam soil, and peat. Analyses of the solid- and liquid-state spectra proved that aniline was readily incorporated into soluble and insoluble humic materials through the formation of anilinohydroquinone, anilinoquinone, anilide, heterocyclic, and imine bonds by nucleophilic addition reactions. Preliminary experiments with aniline/humic conjugates indicate that the imine and anilide bonds are hydrolyzable, while the anilinoquinone, anilinohydroquinone, and heterocyclic N-bonds are not. Recently, Thorn (1997) showed that the same types of bonds are formed when the ADNTs and DANTs are reacted with soil humic acids. Because both 
compost and digester systems favor the breakdown and humification of plant material, it seems likely that a mixture of reactive carbonyl moieties with metabolically reduced TNT should produce large, heterogeneous polymers that are resistant to further degradation.

The transformation of RDX in biotreatment systems is thought to proceed through reduction of nitro groups to yield nitroso-RDX compounds. This is followed by ring cleavage and the formation of methanol, formaldehyde, hydrazines, and $\mathrm{CO}_{2}$ (McCormick et al. 1981). Degradation of RDX and HMX in microbial cultures has also been studied (Binks et al. 1995, Roberts et al. 1996). The formation of hydroxylated metabolites from cleaved rings suggests that there are pathways that could lead to conjugated transformation products. This is in contrast to living plant systems, where RDX is accumulated in tissues without transformation or apparent conjugation (Harvey et al. 1991, Checkai and Simini 1996).

The objectives of this work were to evaluate how various analysis methods differentiate between free and conjugated explosives and their transformation products in composted soil and digester sludge and to investigate the time course of transformation and conjugation.

\section{MATERIALS AND METHODS}

\section{Composts and digester sludges}

Compost samples from aerated windrow composting pilot studies and full-scale treatments at Umatilla Army Depot Activity, Hermiston, Oregon, were obtained from Black and Veatch Waste Sciences, Tacoma, Washington. The compostamendment mixture was composed of (\% by volume) $30 \%$ cow manure, $25.4 \%$ sawdust, $25.4 \%$ alfalfa, $14.3 \%$ chopped potato waste, and $4.9 \%$ chicken manure. The final compost mixture consisted of $70 \%$ amendments and $30 \%$ explosivescontaminated sediment excavated from a driedout explosives waste lagoon. Samples of composted amendments that contained $10 \%$ uncontaminated sediments were also available as controls. Digester sludge was from pilot-scale studies performed by Remediation Technologies (Seattle, Washington) at U.S. Naval Submarine Base, Bangor, Washington. Anaerobic, slurry digestion was performed in lined pits. Contaminated soil, water, an organic carbon source (potato starch), and an inoculum of microbes were mixed in proportions to create a slurry that allowed con- tinuous mixing and heating to above $20^{\circ} \mathrm{C}$. Oxygen initially present in the system was soon consumed and reducing conditions of less than -100 $\mathrm{mV}$ were maintained for 90 days (Tuomi 1995).

\section{Analytical methods}

Solvents used for extractions and analysis were HPLC grade from Alltech Associates, Inc. (Deerfield, Illinois). Concentrated $\mathrm{H}_{2} \mathrm{SO}_{4}$, $\mathrm{Na}_{2} \mathrm{HPO}_{4}$, and $\mathrm{NaOH}$ were reagent grade from J.T. Baker, Inc. (Phillipsburg, New Jersey). Solidphase extraction cartridges (Sep-Pak Poropak $\mathrm{R}_{\mathrm{RX}}$ ) were from Waters Corp. (Millford, Massachusetts).

HPLC analysis was performed using either a Spectra-Physics system (8875 autosampler, 8800 pump, 8490 detector, Hewlett-Packard 3396 integrator) (San Jose, California) or a Waters system (717 autosampler, 616 pump, 600S controller, 996 photodiode array detector, Millenium workstation) (Medford, Massachusetts). A Phenomenex (Torrance, California) Ultracarb 5 ODS(20) (4.6$\mathrm{mm} \times 250-\mathrm{mm}, 5-\mu \mathrm{m})$ reverse-phase column with an Alltech Associates, Inc. (Deerfield, Illinois) C18 guard cartridge was used for the analytical separations. The aqueous/methanol (volume \%/ volume $\%$ ) gradient elution time steps were as follows: start at $85 / 15$, ramp to $65 / 35$ at 8 minutes, ramp to $42 / 58$ at 10 minutes and hold for 13 minutes, ramp to $0 / 100$ at 28 minutes and hold for 7 minutes, ramp down to $85 / 15$ at 40 minutes and hold for 10 minutes before the next injection. The flow rate was $0.8 \mathrm{~mL} /$ minute. Quantification was by peak height performed at $254 \mathrm{~nm}$, while peak identities and purities were assessed by comparing sample and standard UV spectra (200-400 nm) from a diode array detector, and retention times. Further confirmation of analyte identities was performed using a Supelco (Bellefonte, Pennsylvania) cyanopropyl $(\mathrm{CN})(4.6-\mathrm{mm} \times 250-\mathrm{mm}, 5-\mu \mathrm{m})$ column that separates the analytes in a different order than the ODS column. The detection limits for the analytes were approximately $0.1 \mathrm{mg} / \mathrm{kg}$ of dry compost.

Standards for HPLC analysis were made from Standard Analytical Reference Materials obtained from the U.S. Army Environmental Center (Aberdeen, Maryland), except for 2,4DANT and 2,6DANT, which were supplied by Dr. Ronald Spanggord, SRI International (Menlo Park, California).

\section{Solvent extraction}

Compost samples were air-dried overnight, then ground to pass a 2-mm screen. Digester slud- 
ges contained about $50 \%$ solids by weight and had become aerobic by the time of analysis. Sludge samples were air-dried overnight prior to analysis. Subsamples weighing $2.00 \mathrm{~g}$ were added to 40-mL glass vials, which were sealed with Teflonlined caps. A 10-mL aliquot of HPLC-grade acetonitrile was added and the sample mixed on a vortex mixer for one minute. The vials were placed in an ultrasonic bath and sonicated overnight at $30^{\circ} \mathrm{C}$. After sonication, a 10-mL aliquot of aqueous calcium chloride solution $(5 \mathrm{~g} / \mathrm{L})$ was added to hasten flocculation, the sample vortexed briefly, and centrifuged at $2000 \mathrm{~g}$ for five minutes. The aqueous $\mathrm{CaCl}_{2}$ /acetonitrile extract was decanted, filtered, and saved for HPLC analysis. The vials were refilled with fresh $\mathrm{CaCl}_{2}$ /acetonitrile solution, vortexed, centrifuged, and decanted repeatedly (usually three times was adequate) until no more unbound explosives residues or free amino transformation products were detectable by HPLC. The resulting solvent-extracted residues were decanted and air-dried overnight before hydrolysis experiments were initiated.

\section{Acid hydrolysis}

The first of two hydrolysis procedures was an acid hydrolysis. An air-dried residue from the acetonitrile extraction was transferred to a $22-\mathrm{mL}$ vial, $10 \mathrm{~mL}$ of $50 \%$ aqueous $\mathrm{H}_{2} \mathrm{SO}_{4}$ was added, the sample vortexed for one minute, then placed into an ultrasonic bath for six hours at $30^{\circ} \mathrm{C}$. Following sonication, the vial was centrifuged at $2000 \mathrm{~g}$ for five minutes and a 5-mL aliquot of the acid digest removed and neutralized by adding $100 \mathrm{~mL}$ of aqueous, $1.2 \mathrm{M} \mathrm{Na}_{2} \mathrm{HPO}_{4}(\mathrm{pH} 8.4)$. The resulting solution ( $\mathrm{pH}$ 6.5) was pulled through a 6-mL Sep-Pak Porapak RDX $_{\text {cartridge at } 10 \mathrm{~mL} / \text { minute }}$ using vacuum. The cartridge was washed with an additional $20 \mathrm{~mL}$ of reagent-grade water to remove salts, then evacuated for five minutes to remove residual water. A 5-mL aliquot of acetonitrile was added and allowed to drip through the cartridge at $5 \mathrm{~mL} /$ minute. Reagent-grade water $(5 \mathrm{~mL})$ washed through the cartridge into the acetonitrile extract. The mixture was diluted to $10.0 \mathrm{~mL}$ using reagent-grade water and analyzed by HPLC.

\section{Base/acid hydrolysis}

The second hydrolysis procedure combined a base and acid hydrolysis. Solvent-extracted and air-dried samples from the Day- 15 compost and a time series of the digester sludges were transferred to $22-\mathrm{mL}$ vials and treated with $10 \mathrm{~mL}$ of $0.5 \mathrm{M}$ $\mathrm{NaOH}$. The samples were vortex-mixed for three minutes and sonicated overnight at $30^{\circ} \mathrm{C}$. The vials were centrifuged and a 5-mL aliquot of each basic extract of the Day- 15 compost was removed and diluted to $10 \mathrm{~mL}$ with concentrated $\mathrm{H}_{2} \mathrm{SO}_{4}$. The remaining $5 \mathrm{~mL}$ of basic extract was left in the vial with the residue and $5 \mathrm{~mL}$ of concentrated $\mathrm{H}_{2} \mathrm{SO}_{4}$ was added. Acidified residues were sonicated for six hours at $30^{\circ} \mathrm{C}$, centrifuged, and 5-mL aliquots removed and neutralized with $1.2 \mathrm{M}$ $\mathrm{Na}_{2} \mathrm{HPO}_{4}$. As a precaution, 3,5-dinitroaniline (3,5DNA) was added as a surrogate to the neutralized digests to monitor recovery from the Sep-Pak cartridges.

Acid hydrolysis of base-hydrolyzed residues was modified to eliminate the spattering of digestion mixture when concentrated acid was added too quickly. A sample of Day-10 compost was solvent-extracted, rinsed, and base-hydrolyzed as above. A 5-mL aliquot of $-15^{\circ} \mathrm{C} 50 \% \mathrm{H}_{2} \mathrm{SO}_{4}$ was added to the $5 \mathrm{~mL}$ of base-hydrolysis mixture. The heat generated using this procedure did not cause spattering.

\section{Recoveries}

Spike-recovery experiments were performed by adding seven explosives and transformation products dissolved in acetonitrile to field-moist composts, digester sludge, and sand. The spiked concentrations ranged from one to three $\mathrm{mg} / \mathrm{kg}$ (dry material) for one set of triplicate samples, and 25 to $75 \mathrm{mg} / \mathrm{kg}$ for an additional unreplicated set. The acetonitrile was evaporated in a few minutes as the mixtures were homogenized. The air-dried samples were extracted with acetonitrile in accordance with the procedure described earlier.

Neutralization of acid digests of residues sometimes produced a white, gelatinous precipitate. A spike-recovery experiment was performed to determine the relationship between final $\mathrm{pH}$ and recovery. Residues from solvent-extracted compost samples were spiked at $16 \mathrm{mg} / \mathrm{kg}$ with the ADNTs and the DANTs. The samples were immediately base/acid hydrolyzed. The hydrolysates were subdivided and neutralized to $\mathrm{pH} 4.0,5.0$, or 6.0. The 3,5-DNA surrogate was added and the neutralized hydrolysate passed through the solid-phase extraction cartridges.

To evaluate the recovery of the base/acid hydrolysis procedure, $0.5 \mathrm{M} \mathrm{NaOH}$ was added to two solvent-extracted compost samples and sand. Either the initial explosives (HMX, RDX, TNT) or the TNT transformation products were spiked into the mixtures at concentrations ranging from 25 to $75 \mathrm{mg} / \mathrm{kg}$. The mixtures were sonicated overnight 
and then brought to $25 \%$ acid by adding $-15^{\circ} \mathrm{C}$ $50 \% \mathrm{H}_{2} \mathrm{SO}_{4}$ followed by sonicating again for six hours. Hydrolysates were neutralized to $\mathrm{pH} 5.0$ with $\mathrm{Na}_{2} \mathrm{HPO}_{4}$. The 3,5-DNA surrogate was added immediately before solid-phase extraction. An aqueous base solution with no added solids was also treated with the same procedure.

\section{Analysis for triaminotoluene in anaerobic cultures}

One of the transformation products of TNT is triaminotoluene (TAT). It is known to exist in anaerobic systems (Preuss et al. 1993, Ahmad and Roberts 1995); however, its instability and high degree of polarity have made analysis very challenging. A novel separation using a $\mathrm{CN}$ column with either an isocratic or gradient elution with a buffered eluent was developed and tested on bench-scale anaerobic cultures.

The isocratic separation was run on a $\mathrm{CN}$ column (Supelco $4.6 \mathrm{~mm} \times 250 \mathrm{~mm}$ ) at $1.5 \mathrm{~mL} /$ minute of $10 \mathrm{mM}$ phosphate (pH 3.2) / acetonitrile (99 volume $\% / 1$ volume $\%)$. The retention time of the TAT was 7.4 minutes, well away from more polar interferences that occur in digester solutions. TAT is extremely unstable and begins to degrade into multiple compounds that disappear within an hour or two. Standards and samples have to be prepared immediately before analysis. Getting solid TAT completely into solution requires an acetonitrile/buffer mixture. The aqueous samples from digesters must be mixed 50/50 with acetonitrile before injection. A gradient elution that allows the separation of TAT, both diaminoNTs, and the two aminoDNTs as a single merged peak was developed (Table 1).

Table 1. Gradient elution, LC-CN conditions for triaminotoluene. Flow rate $1.5 \mathrm{~mL} / \mathrm{min}$.

\begin{tabular}{cccc}
\hline Time & Milli-Q & ACN & Buffer \\
0 & 0 & 1 & 99 \\
2 & 99 & 1 & 0 \\
8.5 & 60 & 40 & 0 \\
15 & 0 & 1 & 99
\end{tabular}

Restart 20.0

Retention time (minutes)

\begin{tabular}{lc} 
Triaminotoluene & 4.4 \\
2,6DANT & 9 \\
2,4DANT & 10.8 \\
2ADNT & 12.9 \\
4ADNT & 13.1 \\
\hline
\end{tabular}

\section{RESULTS AND DISCUSSION}

\section{Solvent extraction}

The exhaustive, acetonitrile extractions of the time series showed that the concentration of solvent-extractable (free) TNT was rapidly reduced in compost treatments from $2370 \mathrm{mg} / \mathrm{kg}$ on Day 1 to $28.6 \mathrm{mg} / \mathrm{kg}$ on Day 10 , and to $<5 \mathrm{mg} /$ $\mathrm{kg}$ by Day 20. These results agree with previous analyses of the composts (Caton et al. 1994, Pennington et al. 1995). ADNTs decreased with time, while the DANTs increased for ten days before decreasing (Table 2, Fig. 1). Traces levels of the azoxy transformation products of TNT and the nitroso transformation products of RDX were found in a few of the samples. No hydroxylaminodinitrotoluenes were detected.

When $\mathrm{CaCl}_{2}$ /acetonitrile was decanted from samples being extracted, about $10 \%$ of the solvent was retained by the residues. Each repeat decantation with fresh solvent removed about $90 \%$ of the previously retained analytes, but there was no evidence of further dissolution from the solids. Thus, repeat decantations serve only to purify the residue, removing TNT, RDX, and "free" ADNTs and DANTs. This finding agrees with earlier work from Myers.*

The precision of acetonitrile extraction, based on percent relative standard deviation (\% rsd) estimates for triplicate determinations showed no clear dependence on either analyte or concentration. Values ranged from $<1 \%$ to $73 \%$. The high value was an isolated case because the two next highest values were $37 \%$ and $25 \%$. Excluding the one high value and the several cases where $<1 \%$ was found, the remaining 42 estimates gave a pooled rsd of $11.9 \%$ with 84 degrees of freedom.

\section{Acid hydrolysis}

On the first day after initiation of composting, there were already conjugated ADNTs and DANTs that were released by the acid hydrolysis (Fig. 1). The quantities of conjugated transformation products increased for ten days, then gradually decreased to levels that were approximately equal to, or slightly higher than, the Day-1 level. Samples of this compost that had been stored in large plastic bags at ambient temperature for several months were also analyzed. After this aging, the quanti-

\footnotetext{
*Personal communication, K.F. Myers, U.S. Army Engineer Waterways Experiment Station, Vicksburg, Mississippi, 1995.
} 


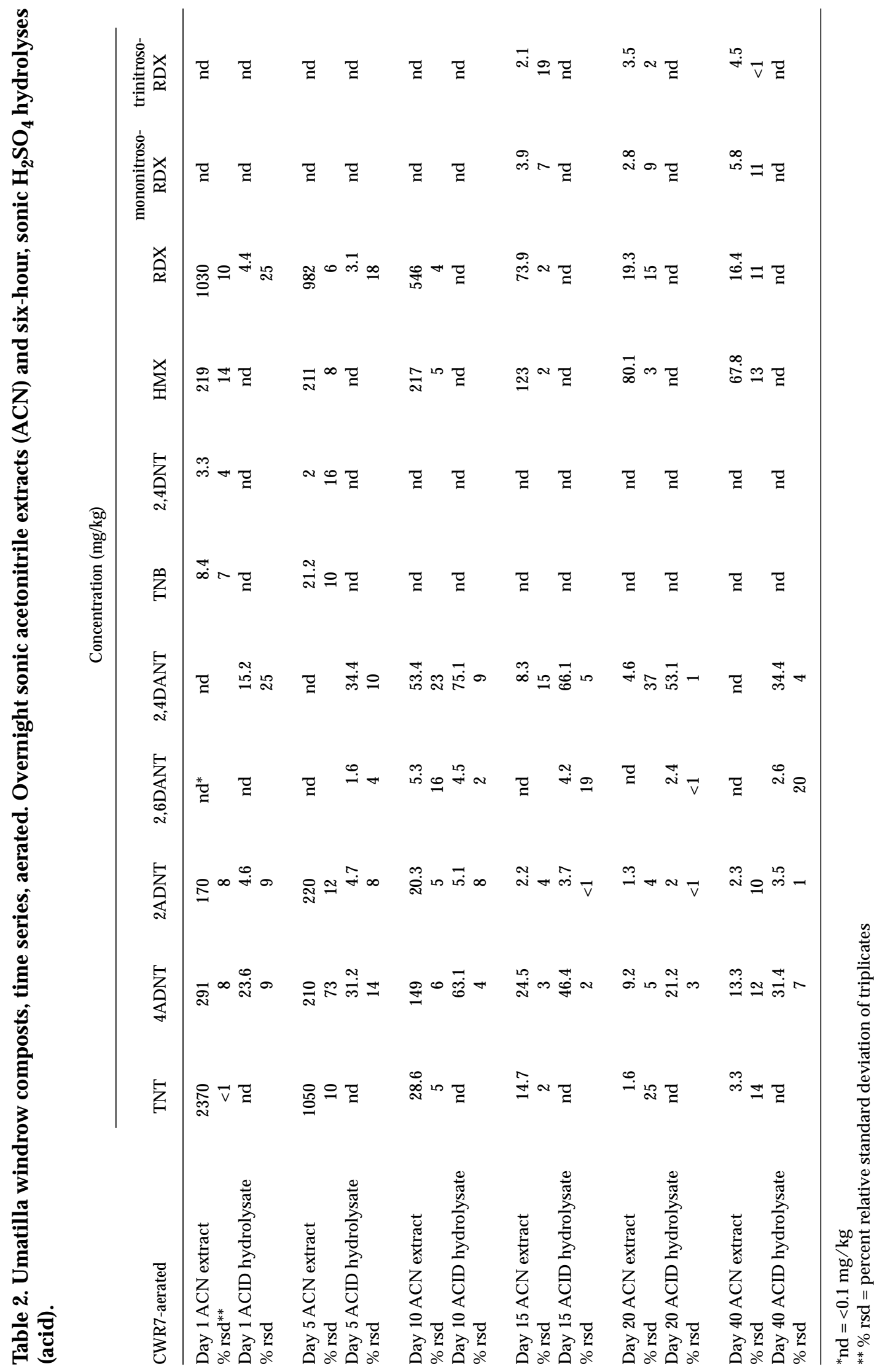




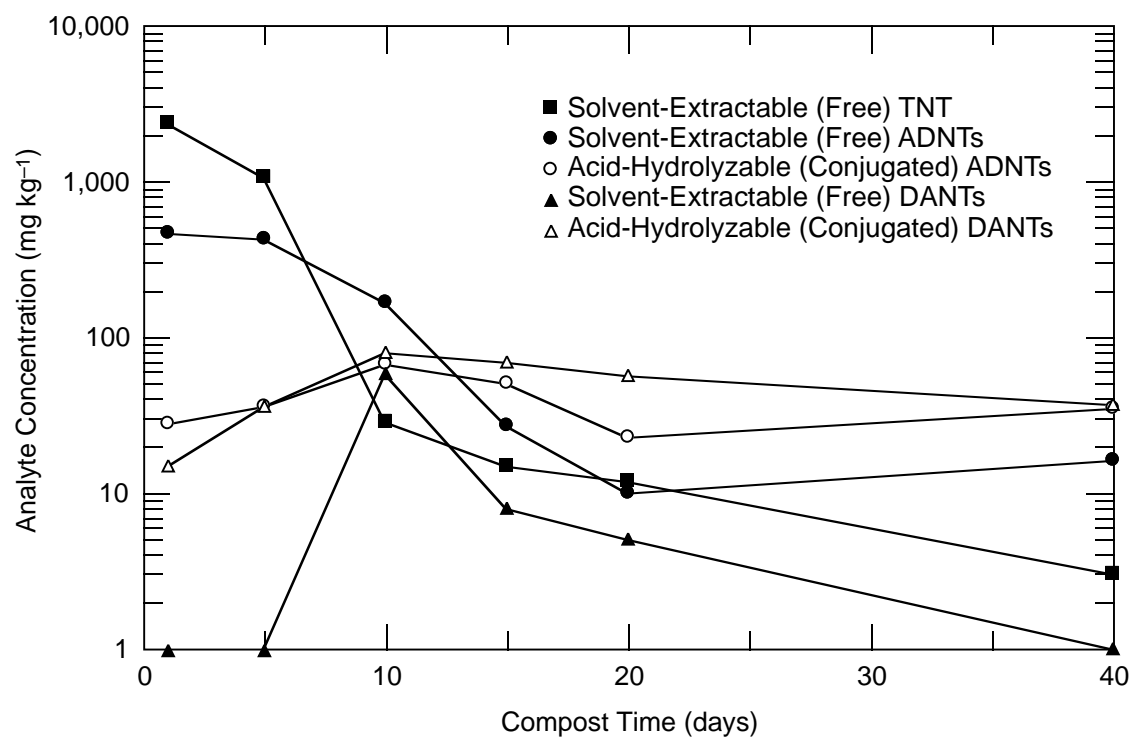

Figure 1. Concentration of free (solvent-extractable) TNT and free and conjugated (acid-hydrolyzable) transformation products recovered from aerated compost.

ties of aminodinitrotoluenes and diaminonitrotoluenes that were released by hydrolysis were further reduced from the Day-40 compost (from 37.8 to $8.1 \mathrm{mg} / \mathrm{kg}$ and from 38.0 to $5.5 \mathrm{mg}$ / $\mathrm{kg}$, respectively), demonstrating that further conjugation of these bound residues continues to occur over time.

Acid hydrolysis of solvent-extracted residues degrades the matrix substantially, but results indicate that no additional TNT, RDX, or HMX is released. The stability of TNT, RDX, HMX, and the ADNTs under conditions used for acid hydrolysis has been demonstrated using compost residues. These results confirm that solvent extraction removes all free TNT, RDX, and HMX from sorption sites deep within the matrix as previously shown for soils (Jenkins and Grant 1987), and confirm the results for compost obtained by Myers.*

\section{Base/acid hydrolysis}

Base/acid hydrolysis experiments were performed using Day- 15 aerated compost and a time series of digester sludge. The quantity of DANTs released from the Day-15 compost by the base hydrolysis was roughly equal to the amount released by the acid-only hydrolysis $(57.2 \mathrm{mg} / \mathrm{kg}$

*Personal communication, K.F. Myers, U.S. Army Engineer Waterways Experiment Station, Vicksburg, Mississippi, 1995. compared to $70.3 \mathrm{mg} / \mathrm{kg}$ ). The base hydrolysis released fewer of the ADNTs than were released by the acid hydrolysis $(19.8 \mathrm{mg} / \mathrm{kg}$ compared to $50.1 \mathrm{mg} / \mathrm{kg}$ ). However, the subsequent acid hydrolysis of the base-hydrolyzed residues released considerably more of the conjugated transformation products $(88.8 \mathrm{mg} / \mathrm{kg}$ of ADNTs and $284 \mathrm{mg}$ / $\mathrm{kg}$ of DANTs) (Fig. 2). The combination of base/ acid hydrolysis increased the total recovery of conjugated ADNTs and DANTs by about a factor of three over acid hydrolysis alone.

Results from acetonitrile extraction of the digester time-series sludges shown in Figure 3 agree with previous determinations (Tuomi 1995). Analysis of the extracts and hydrolysates revealed a pattern of explosives degradation and transformation product conjugation that was similar to that found in the composts.

Control composts (composts with the same starting materials but free of explosives residues) were also extracted, hydrolyzed, and analyzed. Retention times and spectra of all peaks, including the unretained solvent peak, were compared to those from sample composts. When this was done, we did not detect any unidentified TNT transformation products released by hydrolysis.

\section{Recoveries}

The acetonitrile extractions of sand produced recoveries of RDX, HMX, TNT, and 2ADNT from $92 \%$ to $97 \%$ (Table 3). Recovery of 4 ADNT was 


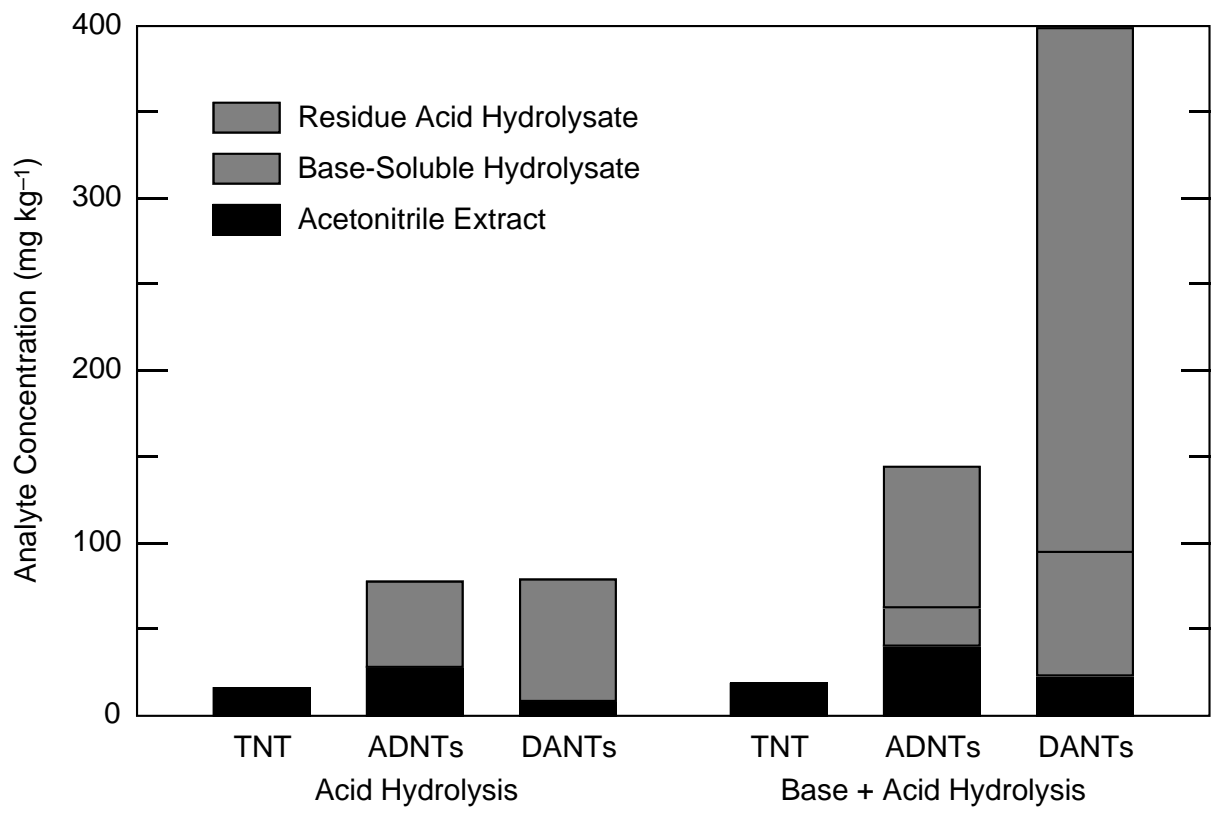

Figure 2. Comparison between the recoveries of ADNT and DANT transformation products from Day-15 aerated compost using acetonitrile extraction, acid digestion, and base/ acid digestion.

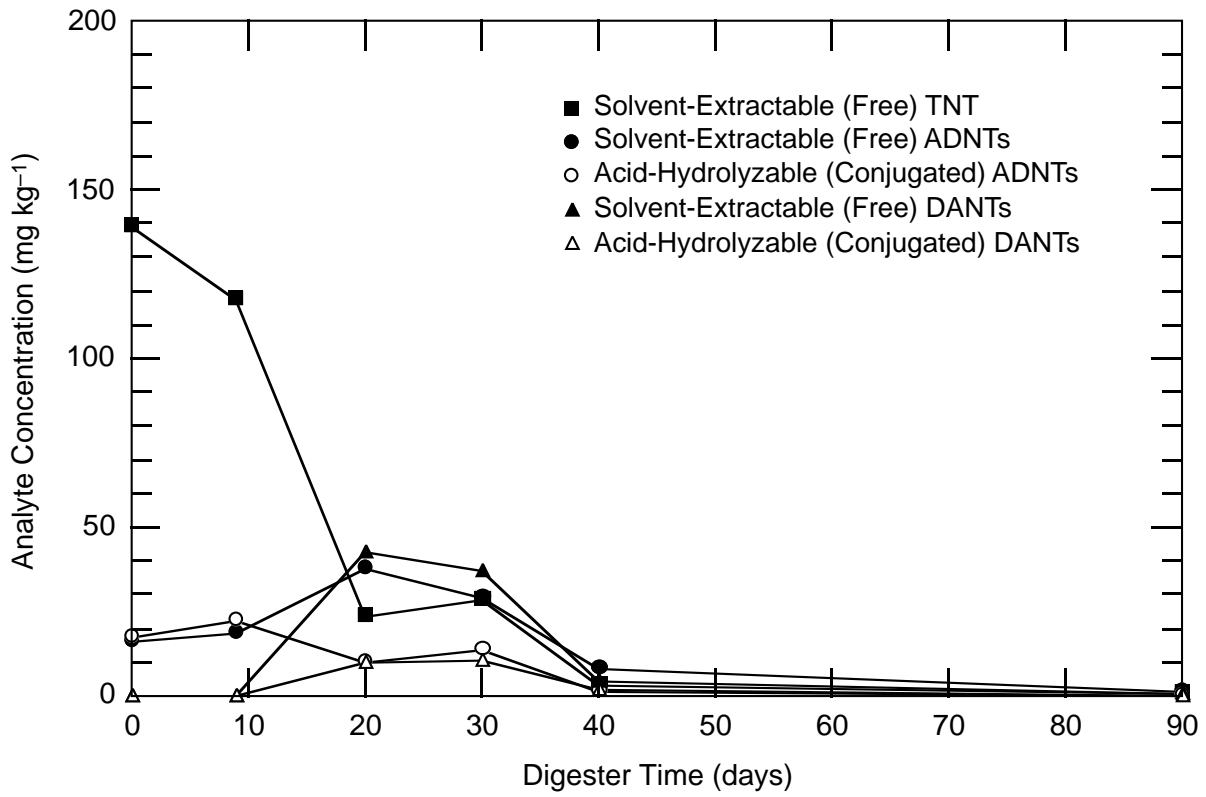

Figure 3. Concentration of free (solvent-extractable) TNT and free and conjugated (base/acid-hydrolyzable) transformation products recovered from digester sludge. 
Table 3. Percent recoveries of spikes by acetonitrile extraction.

\begin{tabular}{|c|c|c|c|c|c|c|c|c|}
\hline & \multicolumn{8}{|c|}{ 1-3 ppm spikes } \\
\hline & TNT & $4 A D N T$ & $2 A D N T$ & $2,6 \mathrm{DANT}$ & $2,4 D A N T$ & $T N B$ & $H M X$ & $R D X$ \\
\hline \multicolumn{9}{|l|}{ Compost } \\
\hline$\%$ recovery & 35 & 91 & 88 & 45 & 27 & 58 & 94 & 97 \\
\hline$\%$ rsd-triplicates & 16 & 8 & 11 & 9 & 12 & 58 & 7 & 11 \\
\hline \multicolumn{9}{|l|}{ Digester-Day 90} \\
\hline$\%$ recovery & 88 & 25 & 40 & 21 & 7 & 96 & 103 & 90 \\
\hline$\%$ rsd & 10 & 8 & 40 & 13 & 12 & 0 & 7 & 2 \\
\hline \multicolumn{9}{|l|}{ Sand } \\
\hline$\%$ recovery & 93 & 82 & 97 & 27 & 11 & 86 & 92 & 97 \\
\hline$\%$ rsd & 3 & 1 & 3 & 8 & 9 & 2 & 2 & 2 \\
\hline \multicolumn{9}{|l|}{$\begin{array}{l}25-75 \text { ppm spikes } \\
\text { Compost }\end{array}$} \\
\hline$\%$ recovery & 72 & 58 & 82 & 92 & 69 & 64 & 82 & 103 \\
\hline
\end{tabular}

$82 \%$. The DANTs were recovered at less than $27 \%$. The recoveries from compost were greater than $94 \%$ for the nitramines (RDX and HMX); however, the recovery of TNT dropped to $35 \%$. This suggests that TNT is transformed and conjugated rapidly by compost. The recoveries of the transformation products were similar to the recoveries from sand, but these values could be inflated by material initially added as TNT. Recoveries from digester sludge were $90 \%$ and above for the nitramines and $88 \%$ for TNT. The recoveries of the TNT transformation products were less than $40 \%$ for the aminodinitrotoluenes and less than $21 \%$ for the diaminonitrotoluenes. Reproducibility for these recovery estimates was best in sand ( $\mathrm{rsd}=$ $5.0 \%$ ) and about $10 \%$ for compost and digester sludge. When the compost was spiked at concentrations ranging from 25 to $75 \mathrm{mg} / \mathrm{kg}$, recoveries

Table 4. Effect of neutralization $\mathrm{pH}$ on percent recovery of hydrolyzed spikes.

\begin{tabular}{|c|c|c|c|c|c|}
\hline & \multicolumn{5}{|c|}{$\%$ recovery of spikes } \\
\hline & $4 A D N T$ & $2 A D N T$ & $2,6 D A N T$ & $2,4 D A N T$ & $3,5 D N A$ \\
\hline \multicolumn{6}{|c|}{ Compost A } \\
\hline $\mathrm{pH} 4$ & $\mathrm{nd}^{*}$ & nd & 14 & 42 & 74 \\
\hline pH 5 & nd & nd & 22 & 76 & 58 \\
\hline pH 6 & nd & nd & 19 & 76 & 10 \\
\hline \multicolumn{6}{|c|}{ Compost B } \\
\hline pH 4 & nd & nd & 10 & 29 & 75 \\
\hline pH 5 & nd & nd & 12 & 39 & 51 \\
\hline $\mathrm{pH} 6$ & nd & nd & 8 & 29 & 28 \\
\hline \multicolumn{6}{|c|}{ Compost C } \\
\hline $\mathrm{pH} 4$ & nd & nd & 20 & 70 & 85 \\
\hline pH 5 & nd & nd & 18 & 72 & 75 \\
\hline $\mathrm{pH} 6$ & nd & nd & 12 & 39 & 57 \\
\hline \multicolumn{6}{|c|}{ Compost D } \\
\hline $\mathrm{pH} 4$ & nd & nd & 16 & 63 & 92 \\
\hline pH 5 & nd & nd & 19 & 76 & 104 \\
\hline $\mathrm{pH} 6$ & nd & nd & 9 & 40 & 61 \\
\hline
\end{tabular}

*nd $=<0.4 \%$ 
Table 5. Recovery of transformation products from compost using $100 \%$ or $50 \% \mathrm{H}_{2} \mathrm{SO}_{4}$ after base hydrolysis.

\begin{tabular}{lcccc} 
& \multicolumn{4}{c}{ Concentration $(\mathrm{mg} / \mathrm{kg})$} \\
\cline { 2 - 5 } & $4 A D N T$ & 2 2ADNT & $2,6 D A N T$ & $2,4 D A N T$ \\
\hline $100 \%$ acid & 63.1 & 5.1 & 4.5 & 75.1 \\
$50 \%$ acid & 19.8 & $<0.1$ & 3.1 & 97.1 \\
\hline
\end{tabular}

of the TNT and diaminonitrotoluenes rose to greater than $69 \%$, while the recoveries of the aminodinitrotoluenes were less than $82 \%$. The difficulty in recovering ADNTs, even in acidified water matrices, has been reported previously (Jenkins et al. 1995).

It was apparent (Table 4) that the $\mathrm{pH}$ must be carefully controlled. A pH of 5.0 is recommended to provide a compromise between absolute recovery of all analytes and a reasonable recovery of the 3,5-DNA surrogate so that solid-phase extraction recoveries can be estimated independently of the hydrolysis/neutralization losses.

Acid hydrolysis from addition of cold $50 \%$ acid resulted in lower recoveries of TNT transformation products than were recovered when $100 \%$ sulfuric acid was used (Table 5). Nevertheless, we recommend the use of $50 \%$ acid because of the potential for injury caused by spattering of hot acid when $100 \%$ acid is used. It is important when assessing these analytical recoveries to realize the dynamic nature of this system. The ADNT and DANT transformation products of TNT are formed, conjugate, and further bind as biotreatment of these soils takes place. Target analytes spiked into these matrices are unstable and recoveries are hence problematic.

None of the untransformed explosives TNT, RDX, and HMX were detected in the hydrolysis spike recovery tests because of their instability in basic solution. Results (Table 6) showed that the procedure recovered from $73 \%$ to $90 \%$ of the ADNTs and from $88 \%$ to $93 \%$ of the DANTs when no solids were present. However, in the presence of compost, no ADNTs were detected and the recoveries of the DANTs dropped to $18 \%-62 \%$. In the presence of sand, the recovery of the ADNTs ranged from 5 to $9 \%$ while the recovery of the DANTs was from $9 \%$ to $40 \%$. For all mixtures that contained solids, the recovery of the 3,5-DNA surrogate that was added to the neutralized hydrolysates immediately before solid-phase extraction ranged from 72 to $88 \%$.

The ability to hydrolyze and recover unbound transformation products from composts changes over the time course of the treatment. Hydrolysis of the aerated composts released the greatest quantities of TNT transformation products during the midpoint of the composting process (Table 2). Hydrolysis of the Day- 40 compost released fewer transformation products, presumably because of further conjugation with formation of functional groups that are more resistant to hydrolysis. The incomplete recoveries of TNT and transformation products that were spiked to composts from the

Table 6. Percent recoveries from base/acid hydrolyzed solution (no solid), compost, and sand. No TNT, RDX, or HMX were recovered.

\begin{tabular}{lccccc} 
& \multicolumn{5}{c}{$\%$ recovery of spikes } \\
\cline { 2 - 6 } & $4 A D N T$ & 2 2ADNT & $2,6 D A N T$ & $2,4 D A N T$ & $3,5 D N A$ \\
\hline $\begin{array}{l}\text { Solution } \\
\% \text { rsd-triplicates }\end{array}$ & 90 & 73 & 88 & 93 & 106 \\
Compost A & nd $^{*}$ & nd & 11 & 62 & 72 \\
$\%$ rsd & & & 21 & 22 & 14 \\
$\begin{array}{l}\text { Compost B } \\
\% \text { rsd }\end{array}$ & nd & nd & 39 & 56 & 87 \\
Sand & & & 32 & 5 & 4 \\
$\%$ rsd & 9 & 5 & 9 & 40 & 88 \\
& $<1$ & $<1$ & $<1$ & 6 & 5
\end{tabular}

${ }^{*}$ nd $=<0.4 \%$ 
end of full-scale operations indicate that fully developed compost has a residual capacity to reduce TNT and conjugate the resulting transformation products. This does not explain the loss of transformation products in the presence of sand with negligible organic carbon $(<0.2 \%)$, but is consistent with losses of these compounds reported for acidified water (Jenkins et al. 1995). None of the azoxy transformation products of TNT were detected.

\section{Analysis for triaminotoluene in anaerobic cultures}

Anaerobic cultures from an experiment at the U.S. Army Construction Engineering Research Laboratories were received in anaerobic serum bottles. The TNT amended cultures had been incubated until all of the TNT, aminoDNTs, and diaminoNTs had been depleted. A sample withdrawn by syringe, mixed with acetonitrile, and analyzed immediately contained TAT, but no other reduction products. An unamended control bottle was blank. The vessel was opened and $1.5 \mathrm{~g}$ of the solid material was solvent-extracted and base/ acid hydrolyzed as above. No TNT or any of its reduction products were recovered by any of the treatments.

\section{CONCLUSIONS}

Previous researchers using radiolabels found that the majority of TNT reduction products were bound in non-solvent-extractable forms. Fractionation of composts (Caton et al. 1994, Pennington et al. 1995) and soils (Comfort et al. 1995) into functional categories indicated that $25-60 \%$ of the unextractable residues were associated with fulvic and humic acids. Our results agree with these findings while providing the necessary identifications of hydrolyzed analytes. In concurrent research, Thorn (1997) is using NMR spectroscopy to identify the bonds that are formed when ${ }^{15} \mathrm{~N}$-labeled aminoDNTs and diaminoNTs are reacted with humic substances, soils, and peat. Identification of which bonds are hydrolyzable will be accomplished by comparing the NMR spectra of the conjugation products before and after hydrolysis. Preliminary experiments with aniline/humic conjugates indicate that the imine and anilide bonds are hydrolyzable by base or acid, while the anilinoquinone, anilinohydroquinone, and heterocyclic N-bonds are not. Thus, it appears that the increased recovery of conjugated transformation products by the base/acid hydrolysis may be due to the disruption of the humic polymers and increased accessibility of bonds.

The transformation of TNT to solvent-nonextractable reduction products appears to go through two stages of covalent conjugation in compost and digester sludge. In the first stage, a significant percentage of the bonds are hydrolyzable by acid or base alone or a combination of base and acid. As processing continues, a second stage occurs in which the bonds are either altered to form different functional groups that are nonhydrolyzable, or additional bonds form as the bound transformation products are further reduced. The termination of treatment as soon as solvent-extractable TNT concentrations drop below a specified action level may stop the conjugation processes at the first, hydrolyzable stage. This may result in the potential for long-term releases of TNT metabolites that might not occur if composting or digesting is continued into the second stage of nonhydrolyzable conjugation. The most current study of the multispecies toxicity of the fully developed composts from the Umatilla pilots (Gunderson et al. 1997) shows that long-term ecological effects are minimal. Some nonlethal effects on plants were observed.

Spike-recovery studies indicated that current methods do not adequately quantify TNT transformation products, particularly at the low concentrations that characterize remediation goals. Current methods are sufficient to remove all of the analytes that are extractable. These may comprise the explosives remaining undissolved in the soil, plus the pool of transformation products that are in the aqueous phase or sorbed and not yet conjugated to the solid phase of the organic matter. However, the transformation products that are released by hydrolysis represent a dynamic pool of weakly conjugated amines that are subject to further reduction and/or bond transformations that eventually become unhydrolyzable as humification continues. Therefore, analyses of bioremediation matrices should be considered as a qualitative descriptor of the progress of humification and the capacity to covalently conjugate transformation products rather than as a quantitative measure of the absolute amounts of various analytes present.

The purpose of the base/acid hydrolysis is to break the bonds between TNT transformation products and organic carbon biopolymers such as humic acid. Detection limit studies showed that a minimum of $0.1 \mathrm{mg}$ of transformation product 
would have to be released from $1 \mathrm{~kg}$ of organic carbon. Therefore, the method is applicable only to high-carbon matrices like compost, digester sludge, or plant and animal tissues. In soil or aquifer materials that contain a few percent or less of organic carbon, there are not enough hydrolyzable products potentially available for analysis by this method.

\section{LITERATURE CITED}

Ahmad, F., and D.J. Roberts (1995) Use of narrow-bore high-performance liquid chromotography-diode array detection for the analysis of intermediates of the biological degradation of 2,4,6-trinitrotoluene. Journal of Chromatography, 93 : 167-175.

Binks, P.R., S. Nicklin, and N.C. Bruce (1995) Degradation of hexahydro-1,3,5-trinitro-1,3,5triazine (RDX) by Stenotrophomanas maltophilia PB1. Applied and Environmental Microbiology, 61: 13181322.

Carpenter, D.F., N.G. McCormick, J.H. Cornell, and A.M. Kaplan (1978) Microbial transformation of ${ }^{14} \mathrm{C}$-labeled 2,4,6-trinitrotoluene in an activatedsludge system. Applied and Environmental Microbiology, 35: 949-954.

Caton, J.E., C.-H. Ho, R.T. Williams, and W.H. Griest (1994) Characterization of insoluble fractions of TNT transformed by composting. Journal of Environmental Science and Health: A, 29: 659-670. Checkai, R.T., and M. Simini (1996) Phytophysical response of crops to irrigation waters containing low concentrations of RDX and TNT: Ecotoxicological implications. 20th Army Science Conference, Norfolk, Virginia.

Comfort, S.D., P.J. Shea, L.S. Hundal, Z. Li, B.L. Woodbury, J.L. Martin, and W.L. Powers (1995) TNT transport and fate in contaminated soils. Journal of Environmental Quality, 24: 1174-1182.

Gorontzy, T., O. Drzyzga, M.W. Kahl, D. BrunsNagel, J. Breitung, E. von Loew, and K.-H. Blotevogel (1994) Microbial degradation of explosives and related compounds. Critical Reviews of Microbiology, 20: 265-284.

Gunderson, C.A., J.M. Kostuk, M.H. Gibbs, G.E. Napolitano, L.F. Wicker, J.E. Richmond, and A.J. Stewart (1997) Multispecies toxicity assessment of compost produced in bioremediation of an explosives-contaminated sediment. Environmental Toxicology and Chemistry, 16: 2529-2537.

Harvey, S.D., R.J. Fellows, D.A. Cataldo, and R.M. Bean (1990) Analysis of 2,4,6-trinitrotoluene and its transformation products in soils and plant tissues by high-performance liquid chromatography. Journal of Chromatography, 518: 361-374.

Harvey, S.D., R.J. Fellows, D.A. Cataldo, and R.M. Bean (1991) Fate of the explosive hexahydro1,3,5-trinitro-1,3,5-triazine (RDX) in soil and bioaccumulation in bush bean hydroponic plants. Environmental Toxicology and Chemistry, 10: 845-855. Jenkins, T.F., and C.L. Grant (1987) Comparison of extraction techniques for munitions residues in soil. Analytical Chemistry, 59: 1326-1331.

Jenkins, T.F., P.G. Thorne, K.F. Myers, E.F. McCormick, D.E. Parker, and B.L. Escalon (1995) Evaluation of the new clean solid phases for extraction of nitroaromatics and nitramines from water. USA Cold Regions Research and Engineering Laboratory, Special Report 95-22.

Kaplan, D.L., and A.M. Kaplan (1982) Thermophilic biotransformations of 2,4,6-trinitrotoluene under simulated composting conditions. Applied and Environmental Microbiology, 44: 757-760.

McCormick, N.G., F.E. Feeherry, and H.S. Levinson (1976) Microbial transformation of 2,4,6trinitrotoluene and other nitroaromatic compounds. Applied and Environmental Microbiology, 31: 949-958.

McCormick, N.G., J.H. Cornell, and A.M. Kaplan (1981) Biodegradation of hexahydro-1,3,5-trinitro1,3,5-triazine. Applied and Environmental Microbiology, 42: 817-823.

Palazzo, A.J., and D.C. Leggett (1986a) Effect and disposition of TNT in a terrestrial plant. Journal of Environmental Quality, 15: 49-52.

Palazzo, A.J., and D.C. Leggett (1986b) Effect and disposition of TNT in a terrestrial plant and validation of analytical methods. USA Cold Regions Research and Engineering Laboratory, CRREL Report 86-15.

Pennington, J.C. (1988) Soil sorption and plant uptake of 2,4,6-trinitrotoluene. Ph.D. thesis. Louisiana State University, Baton Rouge, Louisiana.

Pennington, J.C., C.A. Hayes, K.F. Myers, M. Ochman, D. Gunnison, D.R. Felt, and E.F. McCormick (1995) Fate of 2,4,6-trinitrotoluene in a simulated compost system. Chemosphere, 30: 429438.

Preuss, A., J. Fimpel, and G. Diekert (1993) Anaerobic transformation of 2,4,6-trinitrotoluene (TNT). Archives of Microbiology, 159: 345-353.

Roberts, D.J., F. Ahmad, and S. Pendharkar (1996) Optimization of an aerobic polishing stage to complete the anaerobic treatment of munitionscontaminated soils. Environmental Science and Technology, 30: 2021-2026. 
Spanggord, R.J., K.R. Stewart, and E.S. Riccio (1995) Mutagenicity of tetranitroazoxytoluenes: A preliminary screening in Salmonella typhimurium strains TA 100 and TA 100R. Mutation Research, 335: 207-211.

Thorn, K.A. (1997) Covalent binding of the reductive degradation products of TNT to humic substances examined by ${ }^{15} \mathrm{~N}$ NMR. 213th American Chemical Society National Meeting, 13-17 April, San Francisco, California.

Thorn, K.A., P.J. Pettigrew, W.S. Goldengerg, and E.J. Weber (1996a) Covalent binding of aniline to humic substances. 2. ${ }^{15} \mathrm{~N}$ NMR studies of nucleophilic addition reactions. Environmental Science and
Technology, 30: 2765-2775.

Thorn, K.A., W.S. Goldengerg, S.J. Younger, and E.J. Weber (1996b) Covalent binding of aniline to humic substances. In Humic and Fulvic Acids, ACS Symposium Series \#651, American Chemical Society, Washington, DC, p. 299-326.

Tuomi, E. (1995) Report for the Phase III pilot treatability study located at Subase Bangor, Silverdale, Washington.

Walsh, M.E. (1990) Environmental transformation products of nitroaromatics and nitramines: Literature review and recommendations for analytical method development. USA Cold Regions Research and Engineering Laboratory, Special Report 90-2. 
Public reporting burden for this collection of information is estimated to average 1 hour per response, including the time for reviewing instructions, searching existing data sources, gathering and maintaining the data needed, and completing and reviewing the collection of information. Send comments regarding this burden estimate or any other aspect of this collection of information, including suggestion for reducing this burden, to Washington Headquarters Services, Directorate for Information Operations and Reports, 1215 Jefferson Davis Highway, Suite 1204, Arlington, VA 22202-4302, and to the Office of Management and Budget, Paperwork Reduction Project (0704-0188), Washington, DC 20503.

\begin{tabular}{|l|l|l}
\hline 1. AGENCY USE ONLY (Leave blank) & $\begin{array}{c}\text { 2. REPORT DATE } \\
\text { February } 1999\end{array}$ & 3. REPORT TYPE AND DATES COVERED
\end{tabular}

4. TITLE AND SUBTITLE

February 1999

Investigations of Explosives and Their Conjugated

Transformation Products in Biotreatment Matrices

SERDP Project \#715

6. AUTHORS

Philip G. Thorne and Daniel C. Leggett

7. PERFORMING ORGANIZATION NAME(S) AND ADDRESS(ES)

U.S. Army Cold Regions Research and Engineering Laboratory

72 Lyme Road

Hanover, New Hampshire 03755

9. SPONSORING/MONITORING AGENCY NAME(S) AND ADDRESS(ES)

U.S. Army Strategic Environmental

Research and Development Program

Arlington, Virginia 22203
U.S. Army Environmental Center

Aberdeen Proving Ground, Maryland 21010-5401
8. PERFORMING ORGANIZATION

REPORT NUMBER

Special Report 99-3

11. SUPPLEMENTARY NOTES

12a. DISTRIBUTION/AVAILABILITY STATEMENT

Approved for public release; distribution is unlimited.

Available from NTIS, Springfield, Virginia 22161

12b. DISTRIBUTION CODE

\section{ABSTRACT (Maximum 200 words)}

Samples of soil that had been aerobically composted or anaerobically digested were extracted with solvent, then hydrolyzed with base and then acid. The concentrations of extractable TNT and its monoamino and diamino transformation products fell rapidly after the first days of treatment. Hydrolysis of the solvent-extracted residues released significant quantities of intact transformation products. The concentrations of RDX and HMX were reduced in a similar fashion without the appearance of significant quantities of transformation products. A generalized approach to biotreatment matrices analyses was developed. Spike-recovery studies indicated that analyses of bioremediation matrices should be considered as a qualitative descriptor of the progress of humification and the capacity to covalently conjugate transformation products rather than as a quantitative measure of the absolute amounts of various analytes present.

\begin{tabular}{|c|c|c|c|c|c|}
\hline \multirow[t]{2}{*}{ 14. SUBJECT TERMS } & \multirow{2}{*}{\multicolumn{2}{|c|}{$\begin{array}{l}\text { Compost } \\
\text { Digester } \\
\text { Explosives }\end{array}$}} & \multirow{2}{*}{\multicolumn{2}{|c|}{$\begin{array}{ll}\text { Nitramines } & \text { TNT } \\
\text { Nitroaromatics } & \\
\text { RDX } & \end{array}$}} & $\begin{array}{c}\text { 15. NUMBER OF PAGES } \\
19 \\
\end{array}$ \\
\hline & & & & & 16. PRICE CODE \\
\hline \multicolumn{2}{|c|}{$\begin{array}{l}\text { 17. SECURITY CLASSIFICATION } \\
\text { OF REPORT }\end{array}$} & \multicolumn{2}{|c|}{$\begin{array}{l}\text { 18. SECURITY CLASSIFICATION } \\
\text { OF THIS PAGE }\end{array}$} & $\begin{array}{l}\text { 19. SECURITY CLASSIFICATION } \\
\text { OF ABSTRACT }\end{array}$ & 20. LIMITATION OF ABSTRACT \\
\hline \multicolumn{2}{|c|}{ UNCLASSIFIED } & \multicolumn{2}{|c|}{ UNCLASSIFIED } & UNCLASSIFIED & UL \\
\hline
\end{tabular}

